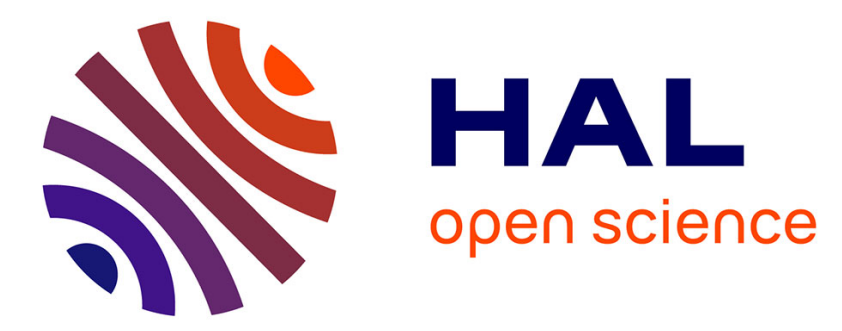

\title{
Hexavalent thiofucosides to probe the role of the Aspergillus fumigatus lectin FleA in fungal pathogenicity
}

Christophe Dussouy, Pierre-Alban Lalys, Aurore Cabanettes, Victor Lehot, David Deniaud, Emilie Gillon, Viviane Balloy, Annabelle Varrot, Sébastien G Gouin

\section{- To cite this version:}

Christophe Dussouy, Pierre-Alban Lalys, Aurore Cabanettes, Victor Lehot, David Deniaud, et al.. Hexavalent thiofucosides to probe the role of the Aspergillus fumigatus lectin FleA in fungal pathogenicity. Organic \& Biomolecular Chemistry, 2021, 19 (14), pp.3234-3240. 10.1039/D1OB00152C . hal-03429198

\section{HAL Id: hal-03429198 https://hal.science/hal-03429198}

Submitted on 15 Nov 2021

HAL is a multi-disciplinary open access archive for the deposit and dissemination of scientific research documents, whether they are published or not. The documents may come from teaching and research institutions in France or abroad, or from public or private research centers.
L'archive ouverte pluridisciplinaire HAL, est destinée au dépôt et à la diffusion de documents scientifiques de niveau recherche, publiés ou non, émanant des établissements d'enseignement et de recherche français ou étrangers, des laboratoires publics ou privés. 


\title{
Hexavalent thiofucosides to probe the role of the Aspergillus fumigatus lectin FleA in fungal pathogenicity.
}

\author{
Christophe Dussouy, ${ }^{a}$ Pierre-Alban Lalys, ${ }^{\mathrm{a}}$ Aurore Cabanettes, ${ }^{\mathrm{b}}$ Victor Lehot, ${ }^{\mathrm{a}}$ David Deniaud, ${ }^{\mathrm{a}}$ Emilie \\ Gillon, ${ }^{b}$ Viviane Balloy, ${ }^{c}$ Annabelle Varrot, ${ }^{\text {b* }}$ and Sébastien G. Gouin. ${ }^{a *}$
}

\begin{abstract}
A. fumigatus is a pathogenic fungus infecting the respiratory system and responsible for a variety of life-threatening lung diseases. A fucose-binding lectin named FleA which has a controversial role in A. fumigatus pathogenesis was recently identified. New chemical probes with high affinity and enzymatic stability are needed to explore the role of FleA in the infection process. In this study, we developed potent FleA antagonists based on optimized and non-hydrolysable thiofucoside ligands. We first synthesized a set of monovalent sugars showing micromolar affinity for FleA by isothermal titration calorimetry. The most potent derivative was co-crystallized with FleA to gain insights into the binding mode in operation. Its chemical multimerization on a cyclodextrin scaffold led to an hexavalent compound with a significantly enhanced binding affinity $\left(K_{\mathrm{d}}=223 \pm 21 \mathrm{nM}\right)$ thanks to a chelate binding mode. The compound could probe the role of bronchial epithelial cells in a FleA-mediated response to tissue invasion.
\end{abstract}

\section{Introduction}

Aspergillus fumigatus is one of the most ubiquitous saprophytic fungi, with an ecological niche in the soil. A. fumigatus abundantly disseminates conidia into the atmosphere, which are easily inhaled into the lungs where they reach the pulmonary alveoli due to their small size. Immunocompetent hosts efficiently clear the conidia out from their respiratory systems by mechanical mucus elimination or innate immunity. However, A. fumigatus is a severe opportunistic pathogen for immunocompromised patients in whom may cause generally fatal lung infections such as invasive aspergillosis or allergic bronchopulmonary aspergillosis. ${ }^{1}$ Increasing resistances to antifungal drug treatments such as the azole class of antifungal agents has fostered research to identify the virulence factors of A. fumigatus.

Carbohydrate-binding proteins (lectins) from microbial pathogens are one of the most common group of receptors involved in the primary steps of cell infection. Lectins expressed by bacteria or fungi and mediating host adhesion are therefore promising targets for the development of therapies based on antiadhesive molecules. Such a strategy is less prone to antimicrobial resistance than existing treatments as selective pressure is not exerted on the microorganisms in the same way. This promising antiadhesive strategy has been particularly explored in recent decades, ${ }^{2-4}$ with several studies reporting

\footnotetext{
a. C. Dussouy, P-A. Lalys, R. V. Léhot, D. Deniaud, S.G. Gouin

Université de Nantes, CNRS, CEISAM UMR, 6230

F-44000, Nantes, France

E-mail: sebastien.gouin@univ-nantes.fr.

b. A. Cabanettes, E. Gillon, A. Varrot

Univ. Grenoble ALpes, CNRS, CERMAVt

38000 Grenoble, France.

c. V. Balloy

Sorbonne Université, Inserm, Centre de Recherche Saint-Antoine, CRSA, Paris,

France
}

significant in vivo effects. Striking decolonization and antibiofilm effects have been reported on bacterial lectins such as the Shiga-like and cholera toxins, 5,6 FimH expressed by pathogenic Escherichia coli strains implicated in urinary tract infections $^{7-9}$ or inflammatory bowel diseases, ${ }^{10-12}$ LecA and LecB expressed by Pseudomonas aeruginosa in the context of lung infections. ${ }^{13-15}$ This promising concept demonstrated on bacteria, has now reached the clinical stage, and may be potentially applied to other classes of pathogens such as fungi. Recently, Armstrong and coll. identified a lectin named FleA (or $\mathrm{AFL}$ ) from $A$. fumigatus which shares homologies with a fucosebinding lectin from the orange peel mushroom Aleuria aurianta. ${ }^{16}$ The role of the lectin is still unclear and it was initially suggested to help the fungus to thrive in decaying matter, to be an important virulence factor involved in the early stage of colonization and to contribute to the inflammatory response. ${ }^{17}$ However, studies have also shown that FleA recognition by bronchial epithelial cells attenuates conidial germination, ${ }^{18}$ and that mucin binding and macrophage killing may prevent $A$. fumigatus pneumonia. ${ }^{19}$ Thus, there is a strong interest in developing molecular antagonists of FleA to fully probe the role of this lectin in the fungal pathogenicity and to assess antagonist therapeutic potential.

X-ray diffraction of FleA co-crystallized with methyl- $\alpha$-Lselenofucoside gave structural insights into this first characterized lectin of pathogenic fungi. ${ }^{17}$ The lectin forms homodimers of six-bladed 8 -propellers. Although the six sugar binding sites (one per monomer) are non-equivalent and have specific oligosaccharide preferences, FleA shows a marked preference for $\alpha$-anomeric fucosides. ${ }^{20} \mathrm{We}$ and others have exploited these specific features to design synthetic multivalent fucosides with the potential ability to interact simultaneously in several binding sites of FleA by a chelate binding mode (Figure 1A). ${ }^{21-23}$ In particular, we recently showed that hexavalent fucosides based on a cyclodextrin (CD) core and optimized oligo(ethyleneglycol) spacers (Figure 1B) are potent FleA antagonists and can decrease spore adhesion to pneumocytes 
at low micromolar concentrations. ${ }^{21}$ In the present work, we designed a second generation of hexavalent fucosides. A small library of monovalent fucosides 1-10 was first designed (Figure 1C, Step 1) and their binding affinity for FleA assessed by isothermal microcalorimetry (ITC) and surface plasmon resonance (SPR) (Step 2). The most promising monovalent ligand could be cocrystallized in complex with FleA and was selected to design the corresponding hexavalent fucoside (Step $3)$.

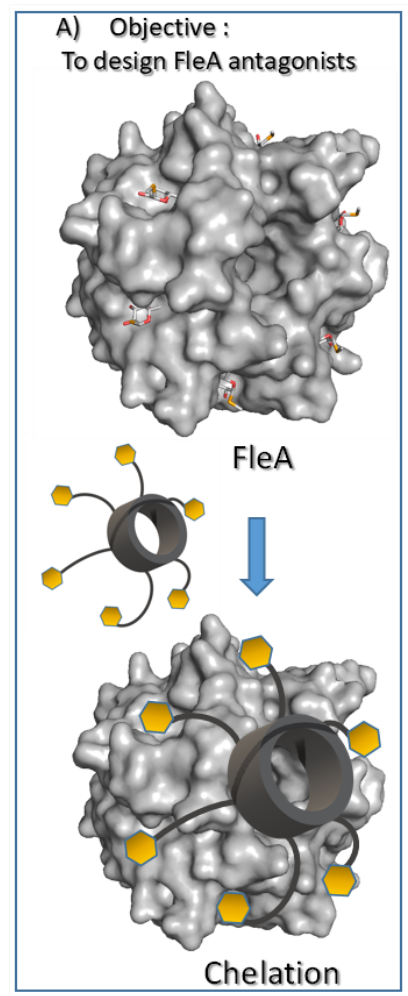

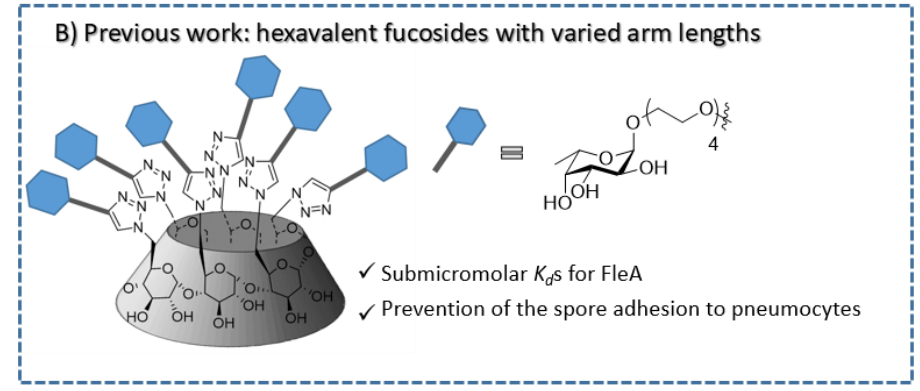

C) This work: Steps 1 to 3 Optimized hexavalent fucosides for FleA

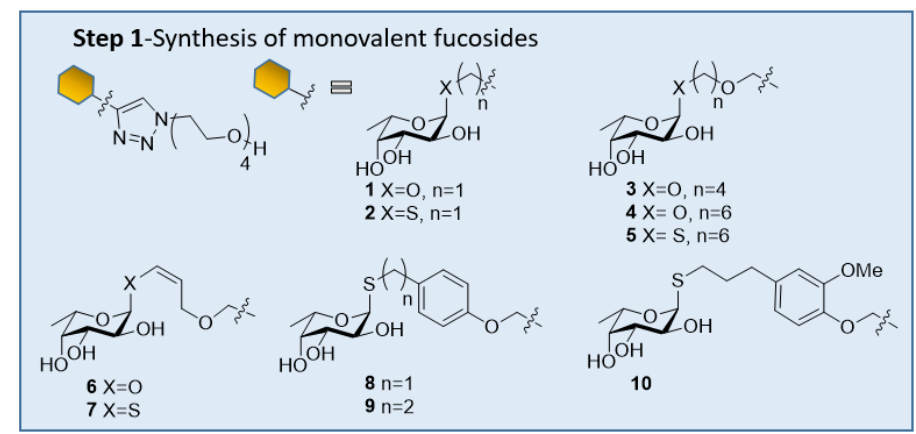

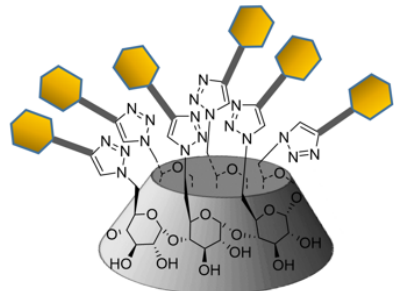

Step 3- Synthesis and evaluation of optimized hexavalent thiofucosides

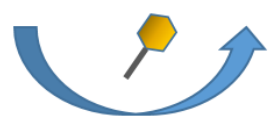

Step 2- Selection of the best FleA antagonists (ITC, X-ray Cristallography)

Figure 1. A) Multivalent fucosides binding the FleA target in a chelate fashion. B) In a previous study, simple fucose sugar was appended to a cyclodextrin core. ${ }^{21} \mathrm{C}$ ) In the present study, we designed a new generation of fucosides with varied hydrophobic groups at the anomeric position. A three-step process was used to obtain optimized and non-hydrolysable heptavalent fucosides.

\section{Results and discussion}

FleA displays a slight preference for the $\alpha$-fucosides compared with the corresponding $\beta$-anomers. ${ }^{20}$ Thus, a Fischer glycosylation protocol was employed in the first step of the chemical synthesis of the monovalent $\alpha$-O-fucosides 1, 3, 4 and 6 (Scheme 1). Sulfuric acid immobilized on silica ${ }^{24}$ catalysed $\alpha$-addition of propargyl alcohols (Synthesis in SI) to fucose, leading to the expected compounds 15-18 after acetate protection. The fucosides were engaged in a coppercatalysed azide-alkyne cyclization in the presence of sodium ascorbate to form exclusively 1,4-regioisomers $19-22$ as shown by the large $\Delta\left(\delta_{\mathrm{c}-4}-\delta_{\mathrm{c}-5}\right)$ observed by ${ }^{13} \mathrm{C} N M R .{ }^{25}$

Excess copper was removed from the crude product after overnight stirring with a chelex resin prior to chromatography on silica gel. The acetate groups were removed using a basic resin to form the monovalent $\alpha-O$ fucosides 1, 3, 4 and 6 .

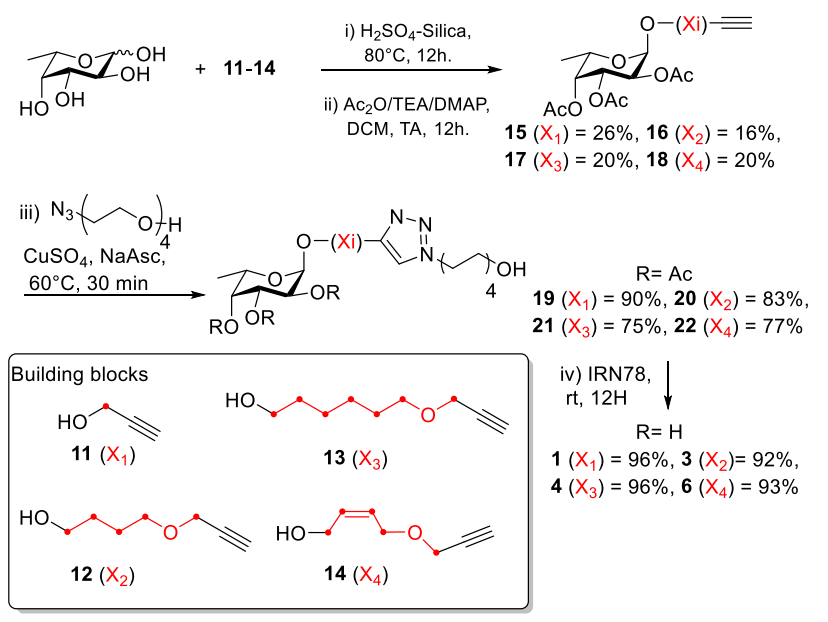

Scheme 1. Chemical synthesis of the monovalent $\alpha$ - $O$-fucosides $1,3,4,6$.

Thiofucosides 2, 5 and 7-10 were obtained from the common intermediate 1-thio- $\alpha$-L-fucopyranose tetraacetate $\mathbf{2 3}^{26}$ (Scheme 2). The thioacetate group was first deprotected as a thiolate $\mathbf{2 4}$ using potassium carbonate and sodium methanethiolate in methanol. Surprisingly, using a mixture of the two bases proved very efficient at forming 24 . The 
thiolate was directly engaged in a thiol-ene click reaction with commercially available vinylic synthon $\mathbf{2 9}$ and $\mathbf{3 0}$ to form 31 and 32 with 57 and 50 \% yields, respectively. Then, the aromatic hydroxyl groups were alkylated with propargyl bromide $\mathbf{2 5}$ in presence of potassium carbonate to form $\mathbf{3 7}$ and 38. Compounds 33-36 were also obtained from the crude thiolate 24, directly engaged in a nucleophilic substitution reaction of bromo- or tosylated alkynyl-armed synthons 25-28 (synthesis in SI). The CuAAc protocol to form 19-22 was repeated with 33-38 and led to good yields of pure cycloadducts 39-44 and the expected thio-fucosides 2, 5, 710 after acetates hydrolysis with IRN78.

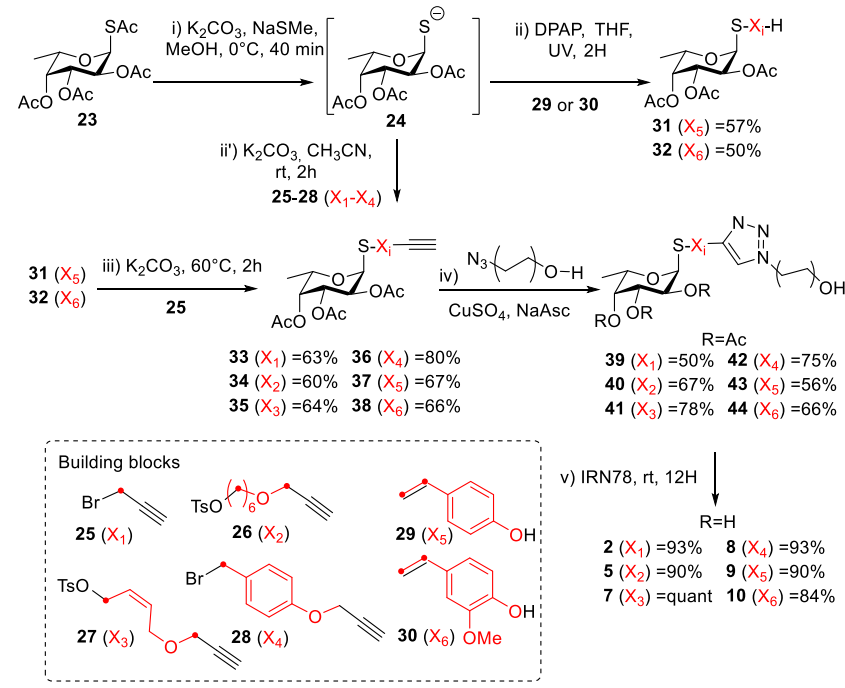

Scheme 2. Chemical synthesis of the monovalent $\alpha$-S-fucosides.

Once we had the monovalent fucosides 1-10 in hand, we assessed their affinity towards FleA by isothermal titration calorimetry (ITC). We initially performed docking experiments with the monovalent fucosides. Unfortunatly, the results (not shown) poorly correlated with ITC ranking. The theoretical predictive efficiency of the compounds is challenging on the FleA target possessing six non-equivalent fucose binding pockets. Dissociations constants $K_{\mathrm{d}}$ and relative affinity values $\left(\beta=\mathrm{K}_{\mathrm{dMF}} / \mathrm{K}_{\mathrm{dcpd}}\right)$ towards $\alpha$ methylfucoside (MF, $\left.K_{d}=110 \mu M\right)^{21}$ are presented Table 1. All of the compounds showed improved potency compared with MF, with $\beta$ values ranging to 1.1 to 5.9. Switching the anomeric oxygen for a sulfur atom was detrimental with thio-compounds 5 and $\mathbf{7}$ showing around two fold higher $K_{\mathrm{d}}$ values compared with the $O$-analogues 4 and $\mathbf{6}$, respectively. This is however not a general rule, as $\mathbf{1}$ and $\mathbf{2}$ with $\mathrm{O}-\mathrm{CH}_{2}$ and $\mathrm{S}-\mathrm{CH}_{2} \quad \mathrm{R}$ groups displayed virtually identical affinity constants. The impact of methylene homologation was shown to be insignificant in the aliphatic series of compounds 1, $\mathbf{3}$ and $\mathbf{4}$ but dramatically reduced FleA affinity when comparing 8 and $\mathbf{9}$ with phenyl rings. Thus, subtly different interactions operate depending on the anomeric substituents and a larger library of fucosides may allow the identification of more potent submicromolar FleA antagonists.
Ligand $8\left(K_{d}=18 \mu \mathrm{M}\right)$, showed a significantly higher affinity for FleA compared with MF or compounds 1-7, 9 and 10. In consequence, we decided to study its binding mode with FleA in greater depth by X-ray crystallography. $\mathbf{8}$ is bound to five out of the six binding sites of FleA (Figure 2). In site 4 , we find a glycerol or a PEG molecule bound, since it is more deeply buried. The binding of compound $\mathbf{8}$ will be inhibited here by steric clashes of the aglycone moiety with the protein and in particular with the side chain of Tyr168. In molecule B, a glycerol moiety is also observed in site 6 that could result in binding difficulties due to the crystal contacts. In site 5, only electron density for the fucosyl moiety is visible. In sites $1-3$, the phenyl moiety of ligand 8 could be modelled in the electron density. In site 1 of molecule A, we observed electron density up to the triazole ring of compound 8 (Figure 2D, section $1 \mathrm{~A}$ ). No electron density was visible for the oligo(ethylene glycol) spacer as it is exposed to the solvent which leads to disorder. The interactions with the fucose moiety are the same as previously described. ${ }^{20}$ The phenyl moiety does not interact directly with the protein but is visible in sites 1-3 where some hydrophobic interactions would stabilize its conformation. In site 1, the aglycone displays two conformations: one where it makes hydrophobic contact with Leu39 and the side chain of Glu41 and one where the triazole ring stacks against the indole ring of His23 (Figure 2B).

Table 1. Binding affinity of compounds 1-10 towards FleA as determined by ITC.

\begin{tabular}{|c|c|c|c|}
\hline Cpd & $\mathbf{R}=$ & $K_{d}(\mu \mathrm{M})$ & $\beta$ \\
\hline MF & & $110 \pm 2$ & - \\
\hline 1 & & $55.8 \pm 1.8$ & 2.0 \\
\hline 2 & s $\widehat{x}$ & $48.8 \pm 4.1$ & 2.2 \\
\hline 3 & & $53.8 \pm 3.3$ & 2.0 \\
\hline 4 & & $59.5 \pm 0.0$ & 1.8 \\
\hline 5 & & $100.7 \pm 0.7$ & 1.1 \\
\hline 6 & & $46.7 \pm 1.9$ & 2.4 \\
\hline 7 & & $90.6 \pm 3.7$ & 1.2 \\
\hline 8 & & $18.5 \pm 0.6$ & 5.9 \\
\hline 9 & & $89.4 \pm 3.2$ & 1.2 \\
\hline 10 & & $103.9 \pm 4.9$ & 1.1 \\
\hline
\end{tabular}



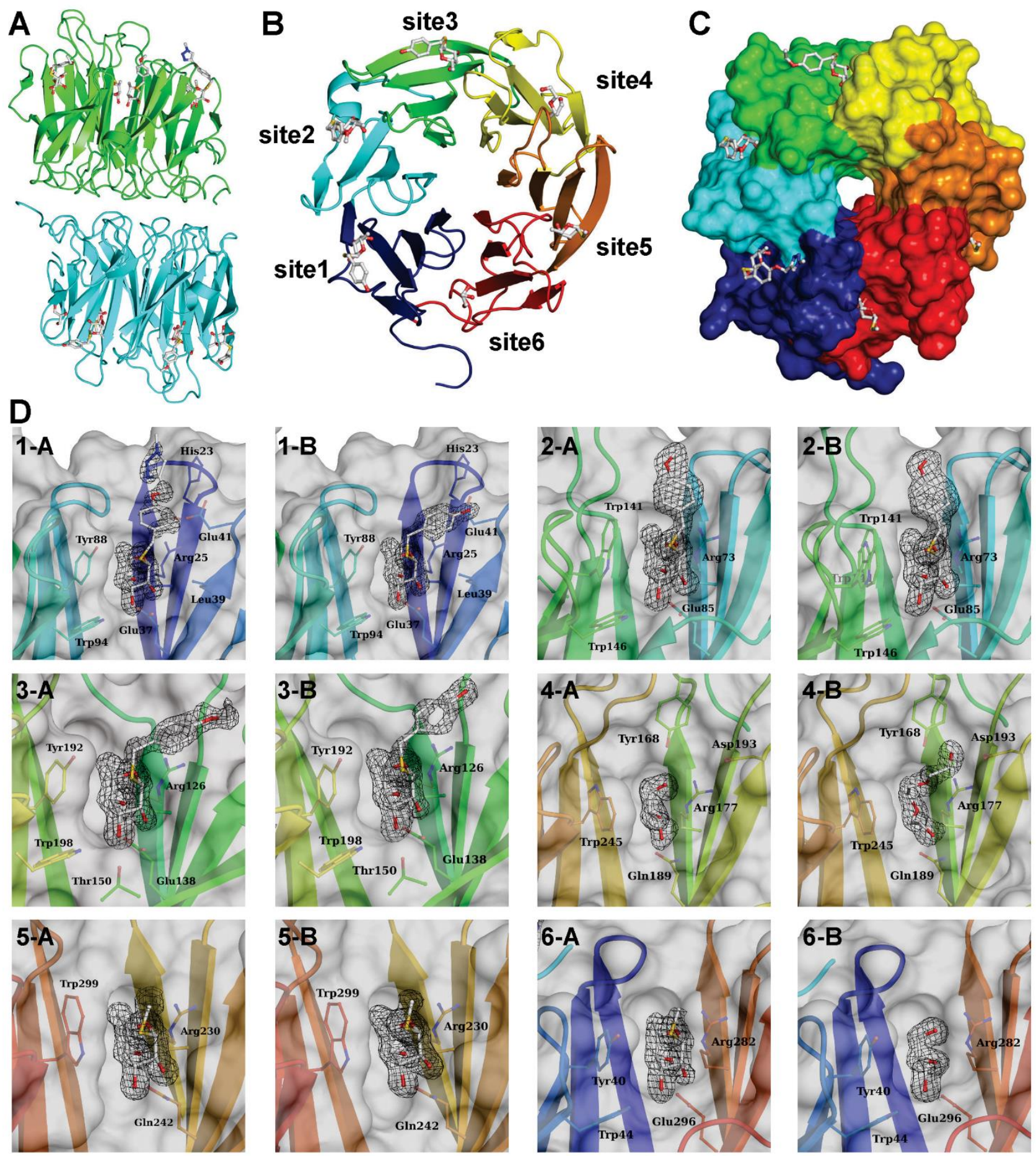

Figure 2. Crystal structure of FleA in complex with Ligand 8. A) Representation of FleA dimer coloured by protomer. B) FleA beta propeller coloured by blade represented in cartoon representation for protomer $B$, and C) in surface representation for protomer A. D) Zoom on FleA binding sites with 2Fo-DFc electron density represented at $1 \sigma\left(0.4 \mathrm{e}^{3}\right)$. Panels are labelled by site and protomer. Ligands are represented in balls and sticks.

Based on the ITC results obtained with monovalent derivatives 1-10, we decided to synthesize the $C D$ fucosides 48 and 49 , which are hexavalent clusters of ligands 2 and 8 displaying the highest FleA affinity of the thiofucosides serie. Several scaffolds may be used for the efficient design of multivalent fucosides. ${ }^{22} \alpha C D$ scaffolds are good candidates due to their hydrophilic nature and rigid core limiting nonspecific interactions with proteins and entropic penalty upon ligand binding. They are easily functionalized at the primary rim to present the sugar ligands with an angular 
spatial restriction. ${ }^{27}$ In a previous study, ${ }^{21}$ we showed that azido- $\alpha C D$ analogues could be easily functionalized by simple alkyne $O$-fucosides using click chemistry techniques to form water-soluble hexavalent $\mathrm{CD}$. We also optimized the spacer arm length, and the best affinity for FleA was obtained with a tetraethyleneglycol spacer. For these reasons, functionalized scaffold $\mathbf{4 5}$ was selected in the present study. Only S-fucosides were clusterized due to their potential inertness to glycosidase hydrolysis. The ligands were grafted by CuAAc on azido-functionalized CD 45, obtained by a previously described protocole. ${ }^{9}$ Acetate deprotection on a basic resin followed by purification on a Sephadex column led to the expected hexavalent compounds $\mathbf{4 8}$ and $\mathbf{4 9 .}$
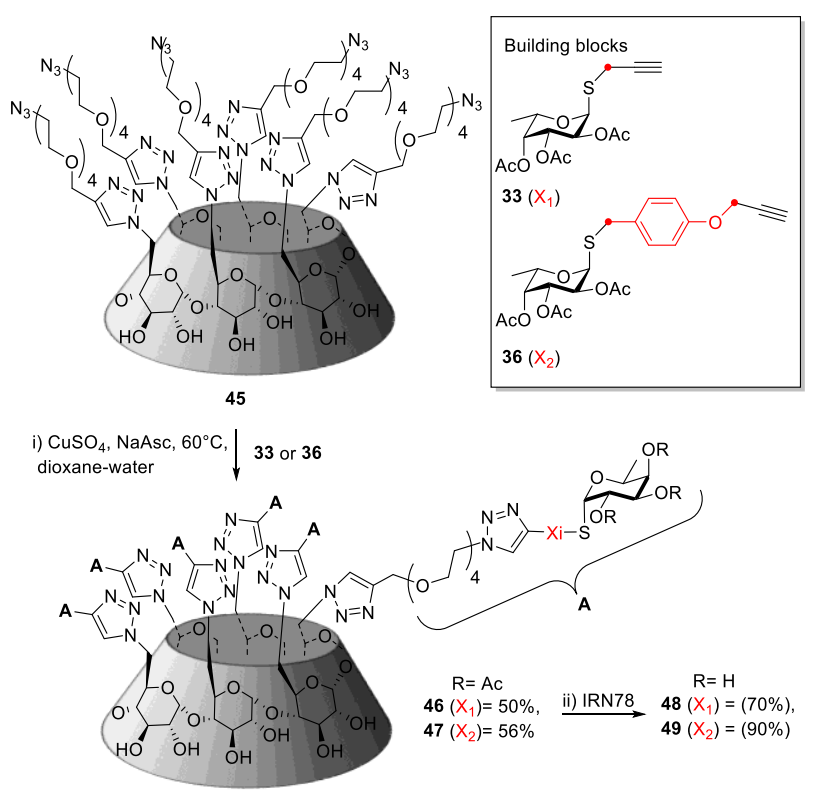

Scheme 3. Chemical synthesis of the hexavalent $\alpha$-S-fucosides 48 and $\mathbf{4 9 .}$

Next, the binding affinity of $\mathbf{4 8}$ and $\mathbf{4 9}$ for FleA was assessed by ITC and compared to MF. In this assay, the reference compound MF showed a similar dissociation constant value as previously published ${ }^{21}$ ( $K_{d}=98$ vs $110 \mathrm{nM}$ ). Surprisingly, the differences in binding affinity of monovalent $\mathbf{2}$ and $\mathbf{8}$ for FleA disappeared when the compounds were multimerized on CD. Indeed, hexavalent derivatives $\mathbf{4 8}$ and $\mathbf{4 9}$ showed rather similar $K_{\mathrm{d}} \mathrm{S}$ measured by ITC (Table 2 ). The fact that the relative inhibitory potency of the fucosides is not conserved when $\mathbf{2}$ and $\mathbf{8}$ are multimerized may be related to the nonequivalence of the six binding sites of FleA. Nevertheless, the hexavalent compounds were much more potent than their monovalent analogues, with $K_{\mathrm{d}} \mathrm{s}$ reaching the nanomolar inhibition level. Each clustered fucoside was more than 400fold more potent compared to MF. This sygnergistic effect may be explained by a partial chelation of the FleA binding sites as suggested by the lower than 1 average stoechiometry $(n)$ values obtained for $\mathbf{4 8}(n=0.814 \pm 0.155)$ and 49 ( $n=0.784 \pm 0.006)$ from three independant ITC measurements.
Table 2. Binding affinity of compounds 48 and $\mathbf{4 9}$ towards FleA as determined by ITC.

\begin{tabular}{l|c|l|l}
\hline $\mathrm{Cpd}$ & $\mathbf{R}=$ & $K_{\mathrm{d}}(\mathrm{nM})$ & $\beta$ \\
\hline MF & -- & $98200 \pm 0$ & - \\
\hline $\mathbf{4 8}$ & r & $238.5 \pm 28.5$ & 412 \\
\hline $\mathbf{4 9}$ & & $223 \pm 21$ & 440 \\
\hline
\end{tabular}

Next we evaluated the potency of $\mathbf{4 9}$ to probe the respective role of FleA in $A$. fumigatus pathogenesis. In a previous study, Balloy and co-workers investigated the mechanisms of A. fumigatus conidia clearance from the lung. ${ }^{18}$ Human bronchoepithelial cells were shown to inhibit the filament formation of extracellular $A$. fumigatus (conidia germination into hyphae) via FleA recognition. FleA from conidia bound at cell surfaces led to cell receptors clustering with enhanced avidity, triggering a fungistatic process that involves the phosphoinositide 3-kinase pathway. This antifungal activity could be abolished by cell-receptors saturation, with recombinant FleA. Here, we assessed if a similar effect could occur after specific binding of $\mathbf{4 9}$ to FleA from conidia. The level of conidia germination into hyphae (filamentation) was followed by the release of galactomannan in the medium (Figure 3). Pre-incubation of BEAS-2B epithelial cells with FleA $(1 \mu \mathrm{M})$ before (1 hour) and during infection (15 hours) with $A$. fumigatus conidia led to a much higher level of filamentation, as previously reported, ${ }^{18}$ and shown by a higher galactomannan level (Figure 3, Af+FleA). Interestingly, a similar trend was observed when $49(100 \mu \mathrm{M})$, instead of FleA, was co-incubated with the conidia and the cells $(A f+49)$. This inhibition of the fungistatic process was however not observed with the less potent FleA antagonist MF at $100 \mu \mathrm{M}(\mathrm{Af}+\mathrm{MF})$. Thus, these preliminary results suggest that optimized multivalent fucosides such as $\mathbf{4 9}$ are valuable probes to studv $A$. fumiqatus pathogenesis.

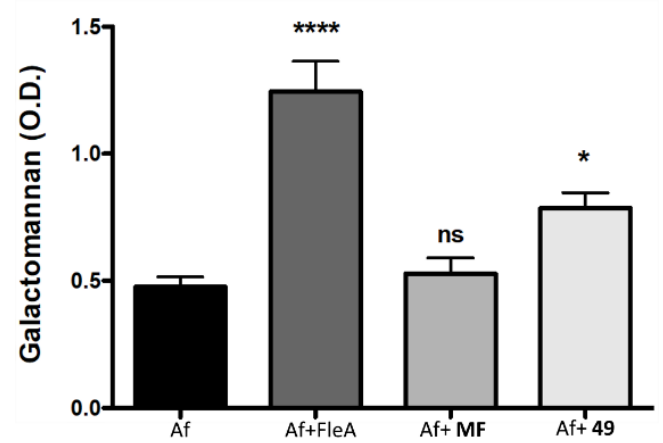

Figure 3. Effect of FleA inhibition on galactomannan release. Values, expressed in optical density (O.D.), are presented as mean $\pm \mathrm{SEM}$ $* * * * p<0.0001,{ }^{*} p<0.05$, ns: not significant (ANOVA test, followed by Bonferroni's multiple comparison test). 


\section{Conclusions}

Fucose-binding lectins expressed by life-threatening pathogens such as $B$. cenocepacia or $A$. fumigatus have attracted attention in view of their potential implications in respiratory infections. ${ }^{19,21,22,28,29}$ The role of the recently identified FleA lectin in $A$. fumigatus pathogenesis is however still unclear. Published studies suggest that FleApromoted binding may actually attenuates $A$. fumigatus virulence, by improving mucocilliary clearance, macrophage killing, and/or inhibition of conidia germination to hyphae. ${ }^{18,19}$ Thus new chemical probes are required to better understand the complex role(s) of FleA during $A$. fumigatus infections. In this work, we developed nonhydrolysable hexavalent thiofucosides with nanomolar affinity for FleA. Insights in the binding mode of the fucoside ligands were provided by X-ray crystallography and ITC experiment. Co-incubation of an optimized hexavalent fucoside (49) with $A$. fumigatus conidia was shown to restore hyphae development, further suggesting a role of the lectin in host response to tissue invasion.

\section{Author Contributions}

Conceptualization, supervision and writing: S.G. and A.V. Revising: D. D. Acquisition and formal analysis: C.D.; P-A. L. and V.L. (chemistry), A.V. crystallography, A.C. and E.G. (ITC), V.B. (cell assay).

\section{Conflicts of interest}

There are no conflicts of interest to declare.

\section{Acknowledgements}

The authors are grateful for access Proxima 1 at SOLEIL Synchrotron, Saint Aubin, France (proposal number 20170827). This work was supported by the SATT OUEST VALORISATION, the French National Research Agency (Glyco@Alps grant no. ANR-15-IDEX-02) and the Centre National de la Recherche Scientifique (CNRS).

\section{Notes and references}

1 J.-P. Latgé, Clin. Microbiol. Rev., 1999, 12, 310-350.

2 S. Cecioni, A. Imberty and S. Vidal, Chem. Rev., 2015, 115, 525-561.

3 D. Deniaud, K. Julienne and S. G. Gouin, Org. Biomol. Chem., 2011, 9, 966-979.

4 N. P. Pera and R. J. Pieters, MedChemComm, 2014, 5, 10271035.

5 G. L. Mulvey, P. Marcato, P. I. Kitov, J. Sadowska, D. R. Bundle and G. D. Armstrong, J. Infect. Dis., 2003, 187, 640649.
6 P. I. Kitov, J. M. Sadowska, G. Mulvey, G. D. Armstrong, H. Ling, N. S. Pannu, R. J. Read and D. R. Bundle, Nature, 2000, 403, 669-672.

7 C. K. Cusumano, J. S. Pinkner, Z. Han, S. E. Greene, B. A. Ford, J. R. Crowley, J. P. Henderson, J. W. Janetka and S. J. Hultgren, Sci. Transl. Med., 2011, 3, 109ra115-109ra115.

8 T. Klein, D. Abgottspon, M. Wittwer, S. Rabbani, J. Herold, X. Jiang, S. Kleeb, C. Lüthi, M. Scharenberg, J. Bezençon, E. Gubler, L. Pang, M. Smiesko, B. Cutting, O. Schwardt and B. Ernst, J. Med. Chem., 2010, 53, 8627-8641.

9 J. Bouckaert, Z. Li, C. Xavier, M. Almant, V. Caveliers, T. Lahoutte, S. D. Weeks, J. Kovensky and S. G. Gouin, Chem. Eur. J., 2013, 19, 7847-7855.

10 D. Alvarez Dorta, A. Sivignon, T. Chalopin, T. I. Dumych, G. Roos, R. O. Bilyy, D. Deniaud, E.-M. Krammer, J. de Ruyck, M. F. Lensink, J. Bouckaert, N. Barnich and S. G. Gouin, ChemBioChem, 2016, 17, 936-952.

11 A. Sivignon, X. Yan, D. A. Dorta, R. Bonnet, J. Bouckaert, E. Fleury, J. Bernard, S. G. Gouin, A. Darfeuille-Michaud and N. Barnich, mBio, 2015, 6, e01298-15.

12 H. Yang, H. C. Mirsepasi-Lauridsen, C. Struve, J. M. Allaire, A. Sivignon, W. Vogl, E. S. Bosman, C. Ma, A. Fotovati, G. S. Reid, X. Li, A. M. Petersen, S. G. Gouin, N. Barnich, K. Jacobson, H. B. Yu, K. A. Krogfelt and B. A. Vallance, Gut Microbes, 2020, 0, 1-19.

13 A. M. Boukerb, A. Rousset, N. Galanos, J.-B. Méar, M. Thépaut, T. Grandjean, E. Gillon, S. Cecioni, C. Abderrahmen, K. Faure, D. Redelberger, E. Kipnis, R. Dessein, S. Havet, B. Darblade, S. E. Matthews, S. de Bentzmann, B. Guéry, B. Cournoyer, A. Imberty and S. Vidal, J. Med. Chem., 2014, 57, 10275-10289.

14 R. Sommer, K. Rox, S. Wagner, D. Hauck, S. S. Henrikus, S. Newsad, T. Arnold, T. Ryckmans, M. Brönstrup, A. Imberty, A. Varrot, R. W. Hartmann and A. Titz, J. Med. Chem., 2019, 62, 9201-9216.

15 F. Pertici, N. J. de Mol, J. Kemmink and R. J. Pieters, Chem. Eur. J., 2013, 19, 16923-16927.

16 S. Kuboi, T. Ishimaru, S. Tamada, E. M. Bernard, S. Kuboi, D. S. Perlin and D. Armstrong, J. Infect. Chemother., 2013, 19, 1021-1028.

17 J. Houser, J. Komarek, N. Kostlanova, G. Cioci, A. Varrot, S. C. Kerr, M. Lahmann, V. Balloy, J. V. Fahy, M. Chignard, A. Imberty and M. Wimmerova, PLoS ONE, 2013, 8, e83077.

18 N. Richard, L. Marti, A. Varrot, L. Guillot, J. Guitard, C. Hennequin, A. Imberty, H. Corvol, M. Chignard and V. Balloy, Sci. Rep., 2018, 8, 1-11.

19 S. C. Kerr, G. J. Fischer, M. Sinha, O. McCabe, J. M. Palmer, T. Choera, F. Yun Lim, M. Wimmerova, S. D. Carrington, S. Yuan, C. A. Lowell, S. Oscarson, N. P. Keller and J. V. Fahy, PLOS Pathog., 2016, 12, e1005555.

20 J. Houser, J. Komarek, G. Cioci, A. Varrot, A. Imberty and M. Wimmerova, Acta Crystallogr. Sect. D, 2015, 71, 442-453.

21 V. Lehot, Y. Brissonnet, C. Dussouy, S. Brument, A. Cabanettes, E. Gillon, D. Deniaud, A. Varrot, P. Le Pape and S. G. Gouin, Chem. - Eur. J., 2018, 24, 19243-19249.

22 D. Goyard, V. Baldoneschi, A. Varrot, M. Fiore, A. Imberty, B. Richichi, O. Renaudet and C. Nativi, Bioconjug. Chem., , DOI:10.1021/acs.bioconjchem.7b00616.

23 S. Thai Le, L. Malinovska, M. Vašková, E. Mező, V. Kelemen, A. Borbás, P. Hodek, M. Wimmerová and M. Csávás, Molecules, 2019, 24, 2262. 
24 B. Roy and B. Mukhopadhyay, Tetrahedron Lett., 2007, 48, 3783-3787.

25 N. A. Rodios, J. Heterocycl. Chem., 1984, 21, 1169-1173.

$26 \mathrm{H}$. Hashimoto, K. Shimada and S. Horito, Tetrahedron Asymmetry, 1994, 5, 2351-2366.

27 S. Liese and R. R. Netz, ACS Nano, 2018, 12, 4140-4147.

28 B. Richichi, A. Imberty, E. Gillon, R. Bosco, I. Sutkeviciute, F. Fieschi and C. Nativi, Org. Biomol. Chem., 2013, 11, 4086.

29 S. Kuhaudomlarp, L. Cerofolini, S. Santarsia, E. Gillon, S. Fallarini, G. Lombardi, M. Denis, S. Giuntini, C. Valori, M. Fragai, A. Imberty, A. Dondoni and C. Nativi, Chem. Sci., 2020, 11, 12662-12670. 